\title{
RESENHA
}

\section{INDÍCIOS DO PORVIR DESOLADOR POR MEIO DA LITERATURA EM DEPOIS DO FUTURO, DE FRANCO BERARDI}

BERARDI, Franco. Depois do futuro. Tradução de Regina Silva. São Paulo: Ubu Editora, 2019.

Visitar e revisitar o catálogo da Ubu Editora deve tornar-se algo cotidiano no que se refere à nossa sede pelo aprimoramento do saber em diversas áreas culturais. Apesar dos relançamentos, em edições pomposas, de clássicos da literatura, o mais cativante da editora é o afã de difundir obras inéditas de pesquisadores brasileiros, ou de trazer à tona produções não traduzidas por aqui anteriormente - havendo livros que centram seus estudos na antropologia, psicanálise, literatura, arquitetura etc. Inserido na categoria de obras não publicadas no Brasil até então, encontra-se Depois do futuro, do filósofo italiano Franco Berardi.

A linguagem do autor não propõe uma abordagem totalmente acadêmica do tema em pauta; deparamo-nos, muitas vezes, com passagens que parecem vir do saber empírico do intelectual. Não que isso seja ruim; pelo contrário, aliás. Num uso da língua pouco hermético, o filósofo italiano, como bem destacou Amanda Mont'Alvão Veloso (2019), em resenha desse mesmo escrito para $O$ Estado de São Paulo, lança mão de conhecimentos da psicanálise, da filosofia, da propaganda, das artes visuais e da literatura a fim de tentar encontrar respostas no que tange à ruptura do sentimento eufórico sobre o futuro, deslizando para o disfórico.

A crença no futuro, de acordo com o filósofo, adentrou o zeitgeist cultural até parte do século XX, sendo descontinuado a partir de 1968. A literatura, como podemos inferir via Berardi no contex to europeu e, principalmente, afirmar mediante Antonio Candido, no contexto brasileiro, antecipou a sensação de melancolia, proliferada mais tardiamente, de modo geral, na população média.

O ponto de partida de Berardi (2019,p. 13) é o artístico. Por meio das vanguardas, mais precisamente o futurismo, houve "o primeiro ato consciente do século que acreditou no futuro." 
Nascido da crença de que a aceleração do modus vivendi das pessoas, mediante uma obstinada modernização dos processos sociais, o futurismo compunha odes às máquinas, sendo elas "os meios de transporte [que] permitiriam chegar a cada centímetro do planeta, que pôde, assim, ser conhecido, marcado, esquadrinhado, submetido ao controle e à exploração.” (BERARDI, 2019, p. 19). Nessa ânsia pela descoberta havia o futuro, isto é, o desconhecido, aquilo que levaria certo período para ser esmiuçado.

O amanhã, nessa equação, estava altamente atrelado ao progresso tecnológico. Somente ele poderia oferecer as ferramentas necessárias com o intuito de compreender lugares obscuros. Fica claro, até agora, que o futuro está pautado na perspectiva de que há muito ainda o que ser feito. Mais detidamente no campo artístico, as vanguardas figuraram o anseio de conceber uma revolução estética; desse modo, a forma realista do romance, por exemplo, tornou-se anacrônica, incomodando estudiosos como Georg Lukács. O filósofo húngaro não via nessas obras vanguardistas, e pós-vanguardistas, o reavivamento das dinâmicas tensionais da História (JAMESON, 2013, p. 4); em outros termos, perdeu-se a totalidade das tensões sociais que a narrativa poderia movimentar.

Berardi (2019, p. 53) vê, nesse momento de deslocamento da figuração do real, um modo de modificar o tratamento artístico a fim de "torná-lo adequado ao modo de ser do real." Se essa busca de inovação formal está intimamente ligada ao possível porvir, ela não parece ser o espírito dos romancistas da época. Como Auerbach (2011, p. 482) afirma, havia uma

[...] questão de posição do escritor diante da realidade do mundo que representa; posição que é, precisamente, totalmente diferente da posição daqueles autores que interpretam as ações, as situações e os caracteres das suas personagens com segurança objetiva, da forma que, anteriormente [nos romances do século XVIII e XIX], ocorria em geral.

A partir, grosso modo, de 1910, os sentimentos são representados, intimamente, ao extremo; a reflexão parece tornar-se o único meio de resistência para aquele indivíduo do romance "que não intervém no mundo, porque perdeu toda a confiança no valor de tal intervenção" (ZÉRAFFA, 2010, p. 51). O mal-estar da personagem destaca-se pelo enorme crescimento da cosmovisão individualista - requisitada pela dinâmica capitalista - e sua inelutável necessidade de viver no mundo, isto é, em relação com os outros: o social, assim, inscreve-se na vida psicológica dramaticamente, às vezes. 
Desse modo, grande parte da sensibilidade dos artistas de então, não enxerga o progresso dos meios de produção euforicamente; ao contrário, eles sintomaticamente irradiam, na escrita, o brutal ritmo das modificações científicas, tecnológicas e econômicas. Quanto mais radical o movimento dessas modificações, mais desnorteamento ele propaga. A intermitente reorganização desses campos leva o sujeito a não os ver mais em conjunto, mas sim em retalhos. Para alguns literatos, por conseguinte, é inconcebível reproduzir o mundo ordenadamente, pois a própria vida é composta caoticamente, o que é sentido no próprio cotidiano. É nele que as personagens sondam o âmago de si mesmas. Do "entrecruzamento, da complementação e da contradição [temporais] surge algo assim como uma visão sintética do mundo" (AUERBACH, 2011, p. 495).

Ora, parece haver, nessas reflexões, um certo descompasso entre revolução formal voltada para o futuro - e o que é representado por meio dessa revolução formal: senão um pessimismo dos escritores, mas um caráter cético em relação aos movimentos histórico-sociais, muito por meio de sua viva observação. Acredita-se que isso fique ainda mais claro na literatura brasileira, a partir da discussão acerca da "possibilidade".

Segundo Berardi (2019, p. 80), a possibilidade "é a dimensão do futuro, admitindo que o futuro possa escapar das correntes lógicas ou históricas da necessidade dialética." Na nossa literatura, principalmente a datar dos anos 30, há uma visão melancólica do presente que parece aporético; ou seja, o futuro é impossível.

De acordo com o sociólogo Sérgio Miceli (2001, p.163), muitos artistas da década de 30 sofreram, grosso modo, com a perda do poder econômico e simbólico dos quais eles participavam, sendo os únicos aptos para representar a ruína; assim:

[...] não há chance de obter nenhuma garantia de objetividade acerca do mundo social a menos que os produtores dessa reconstrução simbólica - sejam eles artistas, escritores ou cientistas - tenham vivido a experiência dramática de serem desalojados da posição social que o seus vinham ocupando, a única maneira de se familiarizarem com outros pontos de vista sem que por isso consigam se desvencilhar do setor da classe dirigente de que são originários.

O painel traçado pelo sociólogo nos dá a dimensão do que seria a alastrada perspectiva negativa sobre o presente, de que Antonio Candido (2017) trata com argúcia em "Literatura e subdesenvolvimento". 
Por meio das reflexões de Mário Vieira de Mello em Desenvolvimento e cultura, Candido (2017, p. 169) disserta acerca das noções de "país novo" - ou país do futuro, segundo as noções de Berardi - em que eram inseridas as nações da América Latina, havendo a "possibilidade de progressos futuros, e "país subdesenvolvido". Neste segundo caso, percebese a tomada de consciência, por parte de alguns intelectuais, de que, em contraste com a esperança de crescimento, destaca-se a pobreza, a atrofia de um país, havendo a percepção de que as revoluções dos anos de 30 não fraturaram totalmente o modus operandi das nossas estruturas de poder.

Entretanto, Antonio Candido (2017, p. 171-2) afirma que a consciência generalizada do subdesenvolvimento - do fracasso, da falta de futuro - vem à tona após a Segunda Guerra Mundial; o romance regionalista de 30, no entanto, "adquiriu uma força desmistificadora que precede a tomada de consciência dos economistas e políticos."

$\mathrm{O}$ entendimento dos escritores de 30 , no que se refere à equação progresso/modernização, é que nela "está ausente qualquer crença na possibilidade de uma transformação positiva do país". São inúmeras as prosas que implicam a modernização como o fruto de tensões histórico-sociais e ontológicas. Desde escritores de cosmovisão católica, mais atrelados à direita, como Jorge de Lima e Lúcio Cardoso, passando pelos não tão engajados politicamente, como José Lins do Rego e Cyro dos Anjos, até os de esquerda, como Graciliano Ramos e Jorge Amado. Parece haver um montante de obras em que não há reconciliação possível com a vida; há, no entanto, o prolongamento do passado narcisista - normalmente nas narrativas em primeira pessoa - que solapa o presente e impede o vislumbre do futuro.

A “esfera do pensável” (BERARDI, 2019, p. 81) está cerceada pela melancolia na literatura, muito antes da cisão marcada pelo filósofo italiano, acontecida 1968 - seja na produção romanesca brasileira, a partir dos autores já mencionados, seja internacionalmente, com Virginia Woolf, William Faulkner, Albert Camus etc. Dizer isso não significa desmerecer as boas reflexões manifestadas em Depois do futuro, principalmente no que tange à falta de homologia evolutiva entre a temporalidade interior moderna e a pós-moderna por meio da tecnologia; há de se reconhecer, no entanto, que, para alguns escritores - em sua aguda sensibilidade - o futuro já havia terminado. 


\section{REFERÊNCIAS BIBLIOGRÁFICAS}

AUERBACH, Erich. Mimesis: a representação de realidade na literatura ocidental. São Paulo: Perspectiva, 2011.

BERARDI, Franco. Depois do futuro. Tradução de Regina Silva. São Paulo: Ubu Editora, 2019. CANDIDO, Antonio. Literatura e subdesenvolvimento. In: A educação pela noite e outros ensaios. São Paulo: Editora Ática, 1989. p. 140-162.

JAMESON, Fredric. The antinomies of realism. London, New York: Verso, 2013.

MICELI, Sergio. Intelectuais e classe dirigente no Brasil (1920-1945). In: Intelectuais à brasileira. São Paulo: Companhia das Letras, 2001. p. 69-281.

VELOSO, Amanda Mont'Alvão. Filósofo italiano analisa como o mundo perdeu a confiança no futuro. Estado de S. Paulo, São Paulo, 13 de abril de 2019. Aliás. Disponível em < https://alias.estadao.com.br/noticias/geral,filosofo-italiano-analisa-como-o-mundo-perdeu-aconfianca-no-futuro,70002787835>. Acesso em: 15 de abril de 2019.

ZÉRAFFA, Michel. Pessoa e personagem: o romanesco dos anos de 1920 aos anos de 1950. Tradução de Luiz João Gaia e J. Guinsburg. São Paulo: Perspectiva, 2010. 